\title{
In-pit crusher location as a dynamic location problem
}

\author{
by M. Paricheh*, M. Osanloo*, and M. Rahmanpour*
}

\section{Synopsis}

The cost efficiency and high reliability of semi-mobile or combined in-pit crushing-conveying (IPCC) and truck systems, compared to conventional truck-shovel systems alone, make them more attractive for use in modern mining operations. Semi-mobile systems, which are the most common systems in open-pit mining, combine the advantages of both systems such that fewer trucks are required, operating costs are lowered, and the operation is environmentally sound. One major aspect of utilizing this system is determining the location of the in-pit crusher and the timing of relocations. Facility location models are rarely used in the mining sector, but these models may be used for solving the in-pit crusher location problem. To this end, the main parameters affecting the IPCC location in open pit mines are reviewed and examples given of how they are applied to a dynamic location-relocation problem. Subsequently, the model is implemented for Sungun copper mine in Iran and the number and the exact time of relocations of the IPCC units determined.

\section{Keywords}

open pit mining, in-pit crusher, IPCC system, dynamic location problem, relocations timing.

\section{Introduction}

Nowadays, compared to the last century, metal prices are more volatile, average and cut-off grades have decreased, and stripping ratios increased. From a mining engineering point of view, many ore deposits with simple access and low capital and operating costs have been exhausted. The remaining deposits are located at depth, with no easy access, which requires high initial capital costs (Osanloo, 2012). Mining at great depths and high tonnages is possible only through open pit mining. Today, more than $80 \%$ of open pit mines in the world use a shovel-truck system for loading-hauling operations (Osanloo, 2010).

With increasing depth, haulage distances increase and the number of loads per truck decreases. As a result, fuel, tyre, and depreciation costs per ton increase. Owing to these factors, open pit mining at great depth (300 to $1000 \mathrm{~m}$ ) using shovel-truck systems faces some technical and economic problems. In-pit crushing-conveying (IPCC) systems have been known in the mining industry for many decades. The idea was introduced in 1956 in Germany. Today, the cost efficiency and high reliability of IPCC make it more appealing than conventional shovel-truck operation, especially in longer life projects with lengthy transportation distances and high production rates (Koehler, 2003). Since 1956, different aspects of this system have been reviewed by many researchers. Barua and Lanergan (1985) developed a computer program that compares the tonnage aspects of various conveyor layouts. They believed that to maximize the economic benefit of lower haulage costs associated with in-pit conveying, one must first minimize the cost of the flatter slope, which is expressed in terms of additional stripping or tied-up ore. Dos Santos and Stanisic (1987) evaluated the design of a high-angle conveyor at the Majdanpek copper mine. Then, Sturgul (1987) applied GPSS (general purpose simulation system) to find the best location of an in-pit crusher. Zimmermann (2006) believes that IPCC presents an opportunity for better and cheaper production. In this context, he considered the applications, case studies, and the economic effects of fully mobile crushing and conveying systems. Konak, Onur, and Karakus (2007) discussed the effects of pit geometry and mine access requirements on crusher site selection, based mainly on minimum haulage distance. They established a trial-and-error process and applied their method to an aggregate mine. Turnbull and Cooper (2009) and Morrison and Lourel (2009) evaluated the IPCC system, and sought to document the options that might be employed to transporting and dumping operations and rank them in terms of their applicability at any mine and their overall practicality. Also, they determined the types of IPCC that would be most appropriate for particular mining operations. Rahmanpour et al., (2014) studied the factors influencing the choice of a proper location of an IPCC and

* Department of Mining and Metallurgical Engineering, Amirkabir University of Technology, Tehran, Iran.

(c) The Southern African Institute of Mining and Metallurgy, 2017. ISSN 2225-6253. Paper received oct. 2015; revised paper received Feb. 2017. 


\section{In-pit crusher location as a dynamic location problem}

investigated in-pit crusher location as a single hub location problem. Roumpos et al., (2014) developed a model for the ideal location of the distribution point of the belt conveyor in continuous surface mines. The model was applied to different scenarios for a lignite deposit with simplified geometry and geology, considering a spatial analysis perspective.

Apart from choosing a suitable type of crushing and conveying system, the system location should also be optimized to reduce operating costs. The crusher site dictates the haulage length for both parts (conveyor and truck) of an IPCC system and the haulage system capacity. The capital and operating costs of an IPCC system thus depend strongly on the crusher locations (Roumpos et al., 2014). Since open pit mining is dynamic in nature and is based on pushback strategy, periodical relocation of the in-pit crusher is inevitable, depending on the production plan. Thus, one major aspect of utilizing this system is to determine the optimum crusher location and the times of relocation. This problem has not been considered yet. Given the nature of open pit mining, in-pit crusher location is essentially a dynamic problem. This paper endeavours to model the problem as a facility location-relocation problem (FLRP). FLRP is a dynamic location model that helps decision-makers to select the initial location and the subsequent relocations. Location-relocation models find the optimum location of a facility in some distinct periods. Each period varies from others and has an individual condition. The model is verified by data gathered from Sungun copper mine in Iran.

\section{Haulage systems in open pit mines}

In a conventional system, the materials inside the pit are excavated and loaded onto trucks and transferred to the crushers, stockpiles, or waste dumps according to the type of material (ore or waste). In most cases, the primary crusher is situated at the edge of the pit. This system is known as an ex-pit crusher. Trucks are well suited to short hauls (less than two miles) and selective mining and dumping (Osanloo, 2010). However, as the mine deepens, they are faced with problems such as:

> Increased haulage distance, requiring more trucks and capital (trucks of $360 \mathrm{t}$ payload cost more than US\$3 million

> As the number of trucks increases, dispatching will become a concern

> Increasing maintenance, repair, and operational costs

> Increasing labour requirement and more supervision.

Haulage costs are always a significant part of capital and operating costs in large open-pit mines. According to Tutton (2009), in a typical large, deep mine using a conventional shovel-truck system, haulage costs constitute more than $45 \%$ of total operating costs, and about $40-50 \%$ of total capital costs (Figure 1). One way of reducing the haulage costs is to shorten the haulage distance by bringing the dumping points (i.e. primary crusher) into the pit. This system is known as in-pit crushing. In-pit crushers can be classified as:

> Semi-mobile operation (known as discontinuous systems): this involves a primary crushing unit inside the pit together with a shovel-truck system. After crushing, the materials is hauled by conveyor to the predetermined destination (processing plant or waste dump). This system is the best option for large open-pit mines (Tutton, 2009)

> Fully mobile operation, where shovels and a mobile crusher are combined. This system has the best productivity and availability. Fully mobile crushing systems are appropriate for horizontally developing surface mines. Figure 2 shows the alternatives for transportation systems in open pit mines.
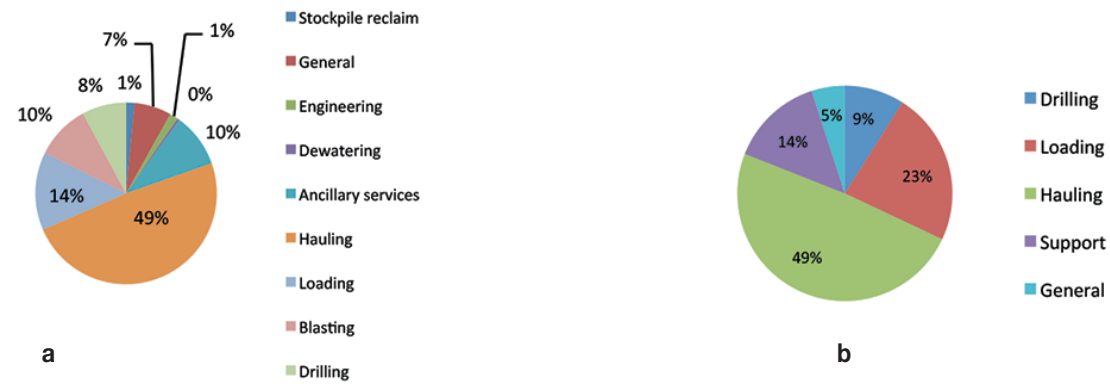

b

Figure 1-(a) Distribution of capital costs, and (b) distribution of operating cost in large open pits (Tutton, 2009)

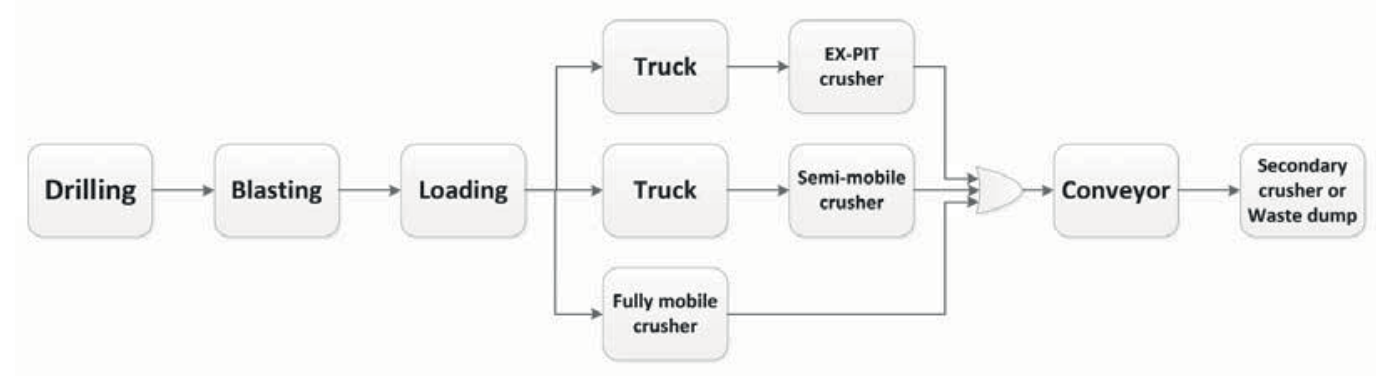

Figure 2-Conventional transportation systems in open pit mines (Tutton, 2009) 


\section{In-pit crusher location as a dynamic location problem}

\begin{tabular}{|l|l|}
\hline \multicolumn{2}{|l|}{ Table I } \\
Factors affecting optimum location and relocation \\
time for IPCCs \\
\hline No. & Factor \\
\hline 1 & Haulage distances and truck operating costs \\
\hline 2 & Mine schedule and block sequences \\
\hline 3 & $\begin{array}{l}\text { Rate of increase in haulage costs with increasing haulage distance } \\
\text { and time (predicted haulage cost) }\end{array}$ \\
\hline 4 & Conveyor operating cost (per ton) vs. truck operating cost (per ton) \\
\hline 5 & Additional haulage cost in relation to pit depth \\
\hline 6 & $\begin{array}{l}\text { Cost for relocation of the system (including engineering, } \\
\text { disassembling, installation, labour, transportation, and overhead } \\
\text { costs, as well as costs of purchasing additional conveyor and } \\
\text { associated equipment) }\end{array}$ \\
\hline 7 & \begin{tabular}{l} 
Scheduled hours and time required for the relocation \\
\hline
\end{tabular}
\end{tabular}

\section{Main factors affecting in-pit crusher location}

An IPCC system must satisfy two competing criteria in order to be the most appropriate selection for a deep open-pit mine: (1) it should technically be able to deliver the required material to the out-of-pit system, and (2) be acceptably costeffective during the operational phase. One major factor in the cost-efficiency of the IPCC system is the optimal in-pit crusher location. Table I summarizes the different criteria that affect the optimal location and time for relocation of an in-pit crusher.

Minimizing the overall haulage operating costs and relocation costs throughout the mine life is the main goal of this investigation. For this purpose:

> The in-pit crusher should be at an optimum distance from the faces and also from waste dumps or plant

> Based on the mine production plan, the amount of material that must be hauled from each working face should be considered. These factors force the in-pit crusher to be located in the centroid of the available working faces (Konak, Onur, and Karakus, 2007; Stughul, 1987; Rahmanpour, 2014). Hence, the capital and operating costs of the truck fleet are reduced

$>$ In addition, the transportation costs increase rapidly each year, not only as a result of wage inflation but also as a result of the increment in haulage distances. In brief, haulage cost is a function of haulage length and time (Benito and Dessoreault, 2008; Roumpos et al., 2014). In the case of open pit mining, to derive a function for haulage cost predictions, one needs to know the mine schedule and have comprehensive information about the haulage system. Thereby, the predicted haulage costs through the mine life will be more realistic

> The conveying distance (or conveying costs) from inpit crusher to an ex-pit destination is another factor that affects haulage costs. With the lower costs of conveyor transport compared to trucking, the in-pit crusher can be at a greater distance from the plant or waste dump site. These conveying costs have not yet been incorporated into the in-pit crusher location problem

$>$ In addition, since extra energy is required by trucks to haul material over a vertical distance, it is necessary to assign a factor into the haulage cost function to consider the extra cost of moving material from the lower benches (Konak, Onur, and Karakus, 2007)

> Owing to the inherent features of open pit mining, the in-pit crusher should be relocated periodically. These repeated displacements take time and add costs to the project. These costs and time intervals should be considered in terms of yearly investment costs and annual operating hours (Morris, 2008). Considering these parameters, the operating and relocating costs can be minimized through optimizing the in-pit crusher location using dynamic location models.

\section{Mathematical model}

Facility location problems (FLPs) are combinatorial optimization problems that help strategic management and decision-making. Combinatorial optimization is the process of finding the optimal solution for problems within a region of feasible solutions. Furthermore, real-world location problems are often large in scale, and are not solvable to optimality within a reasonable time and effort (Rayco, Francis, and Tamir, 1999). FLPs are divided into two main categories: (1) static facility location problems (SFLPs) and (2) dynamic facility location problems (DFLPS). The problem is called static as long as the factors and parameters are fixed and constant with the planning time horizon. If the parameters change during the planning horizon and if there is a considerable amount of capital required for development, then the problem is called dynamic. In most DFLPs, decisionmakers must not only select robust locations, which will effectively serve changing demand over time, but must also consider the timing of expansions and relocation in the long term. From a general viewpoint, FLPs are subdivided in terms of two elements: space and time. Continuous-space, discretespace, and network-space location problems are addressed under the category of SFLPs. On the other hand, timespans constitute the main parts of DFLPs. DFLPs are subdivided into (1) dynamic deterministic facility location problems, (2) facility location/relocation problems (FLRPS), (3) multiperiod facility location problems (MPFLPS), (4) timedependent facility location problems (TDFLPS), (5) stochastic facility location problems, which are relatively similar to probabilistic facility location problems, and (6) fuzzy facility location problems. It should be noted that some types of DFLPs (especially FLRPs, MPFLPs, and TDFLPs) can be converted to each other (many references consider them as a single model: Arabani and Farahani, 2012; Farahani, Drezner, and Asgari, 2009; Erlenkotter, 1981). According to the affecting factors in the previous section, to effectively handle probable changes of open pit mining in a crusher location problem, a dynamic model seems to be indispensable. Additionally, time-dependent parameters involving haulage costs can be predicted easily. Then, it is possible to model the problem by one of the FLRP, MPFLP, or TDFLP models. This paper uses the FLRP model. The binary linear programming form of a dynamic location-relocation problem for determination of the in-pit crusher location is given in Equation [1]. Notations of the model are defined in Table II. 


\section{In-pit crusher location as a dynamic location problem}

\begin{tabular}{|l|l|l|}
\hline \multicolumn{2}{|l|}{ Table $/$ Notations of the FLRP model } \\
\hline Notation & Explanation & Unit/value \\
\hline$r$ & Number of periods & - \\
\hline$p$ & Number of candidate locations & - \\
\hline$m k$ & Number of destinations or faces in period $k$ & - \\
\hline$F_{k i j}$ & $\begin{array}{l}\text { Total haulage operating cost from face } i \text { to } \\
\text { candidate point } j \text { in period } k\end{array}$ & $\$$ \\
\hline$C_{k}$ & $\begin{array}{l}\text { Relocation cost, including engineering, } \\
\text { disassembly, installation, labour, transportation, } \\
\text { and overhead costs, as well as also costs of } \\
\text { purchasing additional conveyor and associated } \\
\text { equipment }\end{array}$ & $\$$ \\
\hline$z_{k j}$ and $y_{k}$ & Binary decision variables & 0 or 1 \\
\hline
\end{tabular}

Objective function:

$$
Z=\operatorname{Min} \sum_{k=1}^{r} \sum_{j=1}^{p} \sum_{i=1}^{m_{k}+1} F_{k i j} z_{k j}+\sum_{k=2}^{r} C_{k} y_{k}
$$

subject to:

$$
\begin{aligned}
& y_{k}=0.5 \sum_{j=1}^{p}\left|z_{k j}-z_{(k-1) j}\right| \quad \forall k \\
& \sum_{j=1}^{p} z_{k j}=1 \quad \forall k \\
& z_{k j}, y_{k}=0 \text { or } 1, \quad \forall k, j
\end{aligned}
$$

Equation [1.1] is the objective function of the model, and is defined as the minimization of the total haulage costs. The first part of the objective function is the operating costs, and the second part is the relocation costs of the IPCC. In order to consider the operating costs of the conveyor from the candidate point $j$ to the mill in period $k$, the value one is added to the third sigma. In the case of system relocation, Equation [1.2] embeds the relocation costs into the model. The constraint in Equation [1.3] ensures that only one of the candidate locations can be selected as the IPCC location. As stated in Equation [1.4], the decision variables are all binary.

The term $F_{k i j}$ is a function of material tonnage in each period and haulage costs per ton in that period. Furthermore, the haulage costs itself $\left(F_{k i j}\right)$ is a function of haulage distance $(d)$ and time $(t)$. In other words, $F_{k i j}$ is a function of haulage distance $(d)$, time $(t)$, and the amount of material to be hauled (Equation [2]):

$$
F_{k i j} ; F_{k i j}(d, t)=T_{k i j} \cdot f_{k i j}(d, t)
$$

where $T_{k i j}$ and $F_{k i j}$ are the total amount of material and haulage costs per ton of materials in period $k$ that should be hauled from site $i$ to destination $j$, respectively.

Prior to applying Equation [2], the truck haulage cost functions should be estimated using any available method, such as that of O'Hara (1980). For the conveyor system, the results of similar investigations at other mine sites should be used or a function developed with respect to local parameters. When the total haulage costs are estimated and substituted in Equation [1], the model can be used to optimize the in-pit crusher location in each period.

\section{Case study}

Sungun copper mine (SCM) is a porphyry deposit and is located in the northwest of Iran. SCM is the second largest copper mine in Iran, with a resource estimated at up to 806 $\mathrm{Mt}$ at an average copper grade of $0.62 \%$. The total mineable reserve of the deposit is about $388 \mathrm{Mt}$ at an average grade of $0.67 \% \mathrm{Cu}$, and the stripping ratio is equal to $1.8: 1$. In the first five years, the annual production is $7 \mathrm{Mt}$, and it reaches $14 \mathrm{Mt}$ in the remaining years. The mined area of SCM is 38.2 $\mathrm{km}^{2}$, half of which will be completely disturbed during the first 27 years of mine life. Some mine infrastructure, including the industrial mine site, concentration plant, belt conveyors, and crushing site are located near the current pit limits. The Pakhir and Sungun rivers flow through the mine area and join the Mian-cafe River and the Ilgene-chai River. The valley of Pakhir on the northern side of the pit is used as a waste dump area. Waste dumps are on the same level as the mine bench into Pakhir. The ore is hauled to an ex-pit crusher on the southeast edge of the pit on horizon $1987 \mathrm{~m}$ (Kavoshgaran, 2003). The waste haulage distance will increase from 1 to $3 \mathrm{~km}$ by the end of the mine life, but the ore haulage distance increases to more than $5 \mathrm{~km}$. Because the waste haulage distance is less than the economical travel distance for trucks (less than 2 miles) throughout the mine life, the dynamic location problem is applied for ore crusher locations. The economic and technical parameters of SCM that have been used in this study are shown in Table III.

\section{Haulage distance calculations}

One primary concern with the installation of an IPCC system is how the conveyors exit the pit. A tunnel, dedicated conveyor ramp, and existing haul roads are three ways by which the conveyors can exit the pit (Turnbull and Cooper, 2009; Morrisson and Lourel, 2009). A feasibility study will determine the best method; then the conveyor specifications (length, angle, and width) and corresponding haulage costs

\begin{tabular}{|c|c|c|c|}
\hline \multicolumn{4}{|c|}{$\begin{array}{l}\text { Table III } \\
\text { Economic and technical parameters of SCM }\end{array}$} \\
\hline Type & Parameter & Value & Unit \\
\hline \multirow{4}{*}{$\begin{array}{l}\text { Economic } \\
\text { parameters }\end{array}$} & $\begin{array}{l}\text { Cost of } 1.6 \mathrm{~m} \text { width } \\
\text { conveyor (Mular, 1992) }\end{array}$ & 3000 & \$ per metre \\
\hline & $\begin{array}{c}\text { Conveyor shipping and } \\
\text { installing cost (Mular, 1992) }\end{array}$ & 25 & $\%$ of conveyor price \\
\hline & Electricity price & 0.03 & $\$ / k W$ \\
\hline & Worker wage & 667 & \$ per man per month \\
\hline \multirow{10}{*}{$\begin{array}{l}\text { Technical } \\
\text { parameters }\end{array}$} & Conveyor capacity & 4000 & $t / h$ \\
\hline & Ramp width & $25-30$ & $\mathrm{~m}$ \\
\hline & Ramp grade & $8-10$ & $\%$ \\
\hline & Max. crusher output size & 25 & $\mathrm{~cm}$ \\
\hline & Existing ex-pit crusher level & 1987 & $\mathrm{~m}$ \\
\hline & First bench level & 2362 & $\mathrm{~m}$ \\
\hline & Pit bottom level & 1600 & $\mathrm{~m}$ \\
\hline & Conveyor width & 160 & $\mathrm{~cm}$ \\
\hline & Ore density & 2.3 & $t / m^{3}$ \\
\hline & Bench height & 12.5 & $\mathrm{~m}$ \\
\hline
\end{tabular}
can be calculated. In this case study, the existing haul roads were selected for routing the conveyor to the pit exit located on level 1987 in the southeast part of mine site. The level is located in the mid-point of the mine depth. Currently, an ex- 


\section{In-pit crusher location as a dynamic location problem}
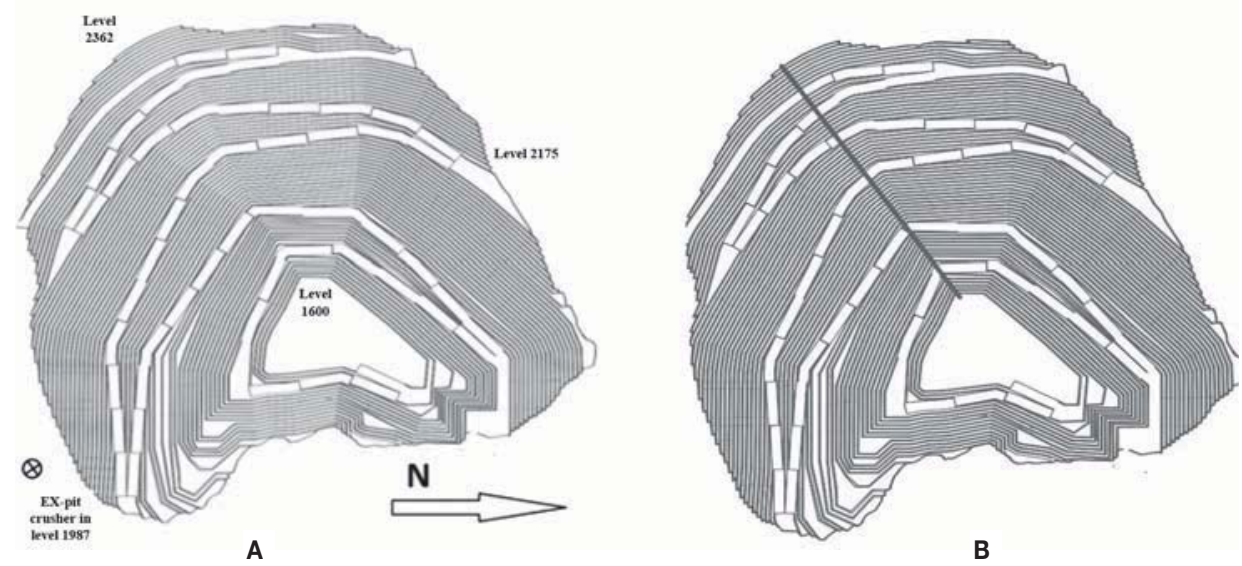

Figure 3-(a) Plan view of pit and ex-pit crusher, and (b) centroid line of all levels

pit crusher is located at this level at a distance of $270 \mathrm{~m}$ from the southern edge of the pit. An overland conveyor line with a length of $1171 \mathrm{~m}$ moves the crushed ore to the concentration plant southwest of the pit.

Considering these issues, if an IPCC is installed in the mine, then the ore should be hauled daily and dumped into an in-pit crusher. After crushing, the ore will be discharged onto a discharge conveyor, which will discharge the crushed ore onto movable conveyors. These conveyors will haul the ore over the existing haul roads out of the pit and deliver the material onto the overland conveyor which goes directly to the concentration plant. Three belts are thus required to complete the transportation process from the pit to concentration plant. Figure 3 a shows a plan view of the pit and the location of the ex-pit crusher. According to the model, the first step is the determination of some candidate location for the crusher. The mine production plan indicates extraction levels and the ore tonnage to be mined. In order to simplify the problem, the geometric centre of each level is assumed as a candidate crusher location. Figure $3 \mathrm{~b}$ shows the centroid line of all mine levels.

Generally speaking, if the IPCC system is going to be applied in the middle of the mine life, then it should be used after the first payback period. This is due to the fact that it would be unwise to reinvest in a project that has not yet returned its initial investment. For this reason, due to a 5-

\begin{tabular}{|c|c|c|c|c|c|c|c|c|c|c|c|c|c|}
\hline \multicolumn{14}{|c|}{$\begin{array}{l}\text { Table IV } \\
\text { Distance from each candidate level to each mining } \\
\text { level in 6th year }(\mathrm{m})\end{array}$} \\
\hline \multirow{2}{*}{$\begin{array}{c}\text { Year } \\
6\end{array}$} & \multicolumn{13}{|c|}{ Candidate level for in-pit crusher } \\
\hline & & 1962 & 1950 & 1937 & 1925 & \begin{tabular}{|l|l|}
512 \\
1912
\end{tabular} & 1900 & 1887 & 1875 & 1862 & 1850 & \begin{tabular}{|l|l|}
0 & 1837
\end{tabular} & 1825 \\
\hline \multirow{7}{*}{ 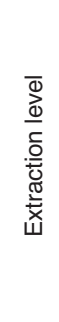 } & 1962 & 575 & 1570 & 1488 & 1469 & 1482 & 1792 & 2155 & 2431 & 2769 & 3189 & 93062 & 2948 \\
\hline & 1950 & 1570 & 575 & 1148 & 1128 & \begin{tabular}{l|l}
3142 \\
\end{tabular} & 1452 & 1815 & 2090 & 2429 & 2849 & 92722 & 2607 \\
\hline & 1937 & 1488 & 1148 & 580 & 720 & 733 & 1044 & 1407 & 1682 & 2020 & 2441 & 12314 & 2199 \\
\hline & 1925 & 1469 & 1128 & 720 & 580 & 413 & 723 & 1087 & 1362 & 1700 & 2120 & $\begin{array}{ll}01994 \\
\end{array}$ & 1879 \\
\hline & 1912 & 1482 & 1142 & 733 & 413 & 595 & 410 & 773 & 1049 & 1387 & 1807 & \begin{tabular}{l|l|l}
7 & 1680
\end{tabular} & 1566 \\
\hline & 1837 & 3062 & 2722 & 2314 & 1994 & 41680 & 1690 & 1727 & 1702 & 1713 & 1833 & \begin{tabular}{l|l}
3 & 585
\end{tabular} & 1265 \\
\hline & 1825 & 2948 & 2607 & 2199 & 1879 & \begin{tabular}{l|l}
9 & 1566
\end{tabular} & 1575 & 1612 & 1587 & 1599 & 1718 & \begin{tabular}{l|l}
8 & 1265
\end{tabular} & 615 \\
\hline
\end{tabular}

year payback period at Sungun, one can investigate the application of IPCC system from the 6th year. Then, depending on the time of the IPCC's application, the dynamic location problem will determine the optimum locations for the remaining years. To improve the solution time, it is assumed that the in-pit crusher should be placed between the highest and lowest levels of mining in each year. Thus, some penalty values are added to each level outside of this boundary. As an example, the distance from the mining point in the 6 th year (centroid of each level) to the candidate point (centroid of each level) in the same year is given in Table IV. For the remaining mine life, these distances are calculated according to the available mine plan.

\section{Incremental truck haulage cost function}

In order to apply the model (Equation [1]), the haulage cost should be specified. To do that, two new mathematical models are developed for prediction of truck and conveyor haulage costs per ton as a function of distance. The unit cost can be calculated by dividing the hourly truck cost by the resulting truck productivity. Truck performance is typically expressed in terms of the hourly production rate (tons per hour), and is calculated considering truck payload and truck total cycle time, which includes spot, load, haul, turn, dump, empty return, wait, and delay times (Benito and Dessoreault, 2008). This method requires comprehensive information on

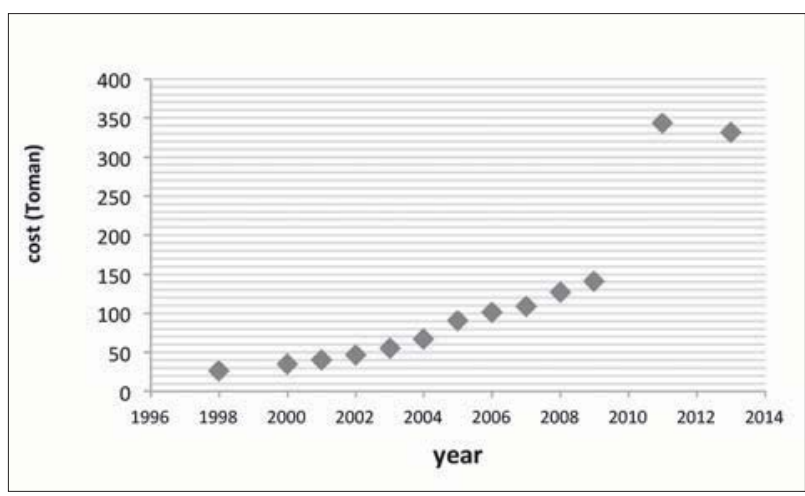

Figure 4-Transportation cost per year (tomans per cubic metre per $500 \mathrm{~m}$ ) 


\section{In-pit crusher location as a dynamic location problem}

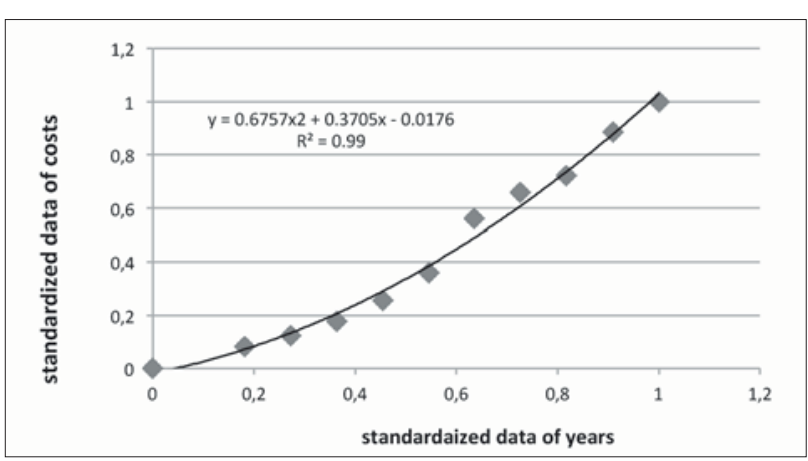

Figure 5-Best fit curve to the standardized data

each component of haulage cost. In this research, annual haulage cost data provided from 1998 to 2013 by the Vice Presidency of Strategic Planning \& Supervision of I.R. Iran (VPSPSI) is used for prediction of truck haulage cost. VPSPSI provides the basic cost structure for contracting companies in all fields. The transportation costs by truck per $500 \mathrm{~m}$ per cubic metre are shown in Figure 4. To calculate the haulage cost for distances beyond $500 \mathrm{~m}$, these costs are increased linearly. After normalizing and smoothing the data, the best curve fitted to the data is selected for prediction of haulage cost per cubic metre per metre. Figure 5 shows the best fit to the normalized data. Moreover, some coefficients such as overhead, road, equipment, weather, and contractor factors are added to the basic costs by contractors who will attend the biddings (Table V). To convert haulage cost from tomans per ton to dollars per ton, the exchange rate is assumed to be 3000 units per dollar.

Finally, the predicted truck haulage cost function per ton of ore per metre in SCM is modelled as in Equation [3]:

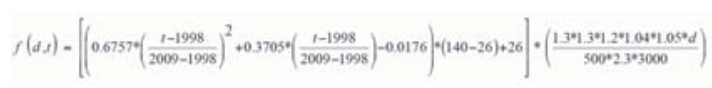

where $d$ is distance in metres, $t$ is year, and $f$ is the annual haulage cost (per ton per metre).

\section{Incremental conveyor haulage cost function}

The conveyor is an inseparable part of the IPCC system. Thus, its design and specifications are very important. Initially, conveyor components for carrying ore in SCM are designed according to the standards of the Conveyor Equipment Manufacturers Association (CEMA). Conveyor operating cost includes spare parts, maintenance, labour, and electricity costs. Calculation of electricity cost depends on belt tension

\begin{tabular}{|l|c|}
\hline \multicolumn{2}{|l|}{$\begin{array}{l}\text { Table } V \\
\text { Conventional coefficients }\end{array}$} \\
\hline Coefficient & Value (\%) \\
\hline Overhead factor & 1.3 \\
\hline Road factor & 1.3 \\
\hline Equipping factor & 1.2 \\
\hline Weather factor & 1.04 \\
\hline Contractor factor & 1.05 \\
\hline
\end{tabular}

and power consumption. Labour, maintenance, and spare parts costs are considered as a percentage of the initial investment cost. After calculation of conveyor power consumption in terms of conveyor length, the incremental annual haulage cost function per ton for the conveyor system is formulated (Equation [4]).

$f(d, t)=\left(P_{K \pi}{ }^{*} \mathrm{AOPH} * 0.03+\left(2 * 2 * 10^{6 *} 12\right) / 3000+0.06^{*} d^{*} 3000^{*} \mathrm{C}_{\text {mide }}(t)\right) / 14^{*} 10^{6}$

where $f$ is yearly conveyor operating cost per ton per unit length of the conveyor, $P_{K W}$ is power required for transportation of ore over a distance of $d$ metres, AOPH is the yearly operating hours (in this case $3600 \mathrm{~h}$ ), $C_{\text {index }}(t)$ is the predicted Marshall and Swift cost index for the year $t$, and $14^{*} 106$ is the yearly ore production of Sungun. The Marshall and Swift equipment cost index was created to facilitate comparisons between two previous quarters or years. Index comparisons are developed by dividing the index for the date for which a cost is desired by the index for the date of the known cost and multiplying the resulting factor by the known cost (Mular, 1992).

\section{Results}

The dynamic location mathematical model presented in Equation [1] is adapted to match the case of Sungun. In this case, $r$ is equal to 22 (from year 6 to 27), $p$ is equal to 47 (number of candidate levels) and $C_{k}$ is equal to $\$ 1.5$ million (average of all probable periodic investment costs for additional conveyors plus $25 \%$ of this cost as engineering, disassembling, relocating and assembling costs). Then, Equations [3] and [4] are applied to calculate the yearly haulage operating cost from each face to candidate levels from year 6 to the end of mine life. The problem is modelled and solved in GAMS (General Algebraic Modeling System). GAMS is a high-level modelling system for mathematical optimization which is designed for modelling and solving linear, nonlinear, and mixed integer optimization problems. Input parameters in an Excel ${ }^{\circledR}$ sheet are sent to the software as a $145^{*} 47$ matrix. Cplex optimizer is used to solve the model. Cplex is a solver that is designed to solve large and difficult problems quickly with minimal user intervention. Depending on the time of application of the IPCC system in the mine, the solution will provide the crusher location and optimum time for the system relocations. A sensitivity analysis was performed for the parameter of relocation costs.

Optimum locations for the in-pit crusher in different years of mine life, depending on the time of applying the system, are shown in Table VI. The first column shows the years, and the first row presents the year when the IPCC system is applied. Each number in the table presents the optimum level where the IPCC system should be installed. As an example, if the system is used from the 10th year, in the first year the in-pit crusher should be located on level 1975, and in the next year it should be relocated to level 1925. Similarly, the in-pit crusher should be located on 12 different levels to the end of mine life and the system should be relocated 11 times.

Running time in seconds (Intel ${ }^{\circledR} \mathrm{Core}^{\mathrm{TM}}$ i5-2450 CPU at $2.5 \mathrm{GHz}$ ) was less than 300 seconds. By increasing the number of periods and the corresponding faces and candidate points, the numbers of variables increases, but this does not change the running time significantly. 


\section{In-pit crusher location as a dynamic location problem}

\begin{tabular}{|c|c|c|c|c|c|c|c|c|c|c|c|c|c|c|c|c|c|c|c|c|c|c|}
\hline \multicolumn{23}{|c|}{$\begin{array}{l}\text { Table } \mathrm{VI} \\
\text { Optimum locations depending on time fo }\end{array}$} \\
\hline \multicolumn{23}{|c|}{ Year of mine life considered for system application } \\
\hline Year & 6 & 7 & 8 & 9 & 10 & 11 & 12 & 13 & 14 & 15 & 16 & 17 & 18 & 19 & 20 & 21 & 22 & 23 & 24 & 25 & 26 & 27 \\
\hline 6 & 1912 & & & & & & & & & & & & & & & & & & & & & \\
\hline 7 & 1912 & 1912 & & & & & & & & & & & & & & & & & & & & \\
\hline 8 & 1912 & 1912 & 1912 & & & & & & & & & & & & & & & & & & & \\
\hline 9 & 1912 & 1912 & 1912 & 2025 & & & & & & & & & & & & & & & & & & \\
\hline 10 & 1975 & 1975 & 1975 & 2025 & 1975 & & & & & & & & & & & & & & & & & \\
\hline 11 & 1925 & 1925 & 1925 & 1925 & 1925 & 1925 & & & & & & & & & & & & & & & & \\
\hline 12 & 1925 & 1925 & 1925 & 1925 & 1925 & 1925 & 1912 & & & & & & & & & & & & & & & \\
\hline 13 & 1887 & 1887 & 1887 & 1887 & 1887 & 1887 & 1887 & 1887 & & & & & & & & & & & & & & \\
\hline 14 & 1825 & 1825 & 1825 & 1825 & 1825 & 1825 & 1825 & 1825 & 1825 & & & & & & & & & & & & & \\
\hline 15 & 1825 & 1825 & 1825 & 1825 & 1825 & 1825 & 1825 & 1825 & 1825 & 1800 & & & & & & & & & & & & \\
\hline 16 & 1912 & 1912 & 1912 & 1912 & 1912 & 1912 & 1912 & 1912 & 1912 & 1912 & 1912 & & & & & & & & & & & \\
\hline 17 & 1912 & 1912 & 1912 & 1912 & 1912 & 1912 & 1912 & 1912 & 1912 & 1912 & 1912 & \begin{tabular}{|l|}
1875 \\
\end{tabular} & & & & & & & & & & \\
\hline 18 & 1862 & 1862 & 1862 & 1862 & 1862 & 1862 & 1862 & 1862 & 1862 & 1862 & 1862 & 1875 & 1862 & & & & & & & & & \\
\hline 19 & 1812 & \begin{tabular}{|l}
1812 \\
\end{tabular} & 1812 & 1812 & 1812 & 1812 & 1812 & 1812 & 1812 & 1812 & 1812 & 1812 & 1812 & 1812 & & & & & & & & \\
\hline 20 & 1812 & 1812 & 1812 & 1812 & 1812 & 1812 & 1812 & 1812 & 1812 & 1812 & 1812 & 1812 & 1812 & 1812 & 1775 & & & & & & & \\
\hline 21 & 1775 & 1775 & 1775 & 1775 & 1775 & 1775 & 1775 & 1775 & 1775 & 1775 & 1775 & \begin{tabular}{|l|}
1775 \\
\end{tabular} & 1775 & 1775 & 1775 & 1775 & & & & & & \\
\hline 22 & 1775 & 1775 & 1775 & 1775 & 1775 & 1775 & 1775 & 1775 & 1775 & 1775 & 1775 & 1775 & 1775 & 1775 & 1775 & 1775 & 1750 & & & & & \\
\hline 23 & 1737 & \begin{tabular}{|l|l}
1737 \\
\end{tabular} & \begin{tabular}{|l|}
1737 \\
\end{tabular} & \begin{tabular}{|l|}
1737 \\
\end{tabular} & 1737 & \begin{tabular}{|l|}
1737 \\
\end{tabular} & $\mid 1737$ & \begin{tabular}{|l|}
1737 \\
\end{tabular} & \begin{tabular}{|l|}
1737 \\
\end{tabular} & $\mid 1737$ & 1737 & 1737 & \begin{tabular}{|l|}
1737 \\
\end{tabular} & \begin{tabular}{|l|l|}
1737 \\
\end{tabular} & 1737 & 1737 & 1750 & 1737 & & & & \\
\hline 24 & 1725 & 1725 & 1725 & 1725 & 1725 & 1725 & 1725 & \begin{tabular}{|l|}
1725 \\
\end{tabular} & \begin{tabular}{|l|}
1725 \\
\end{tabular} & 1725 & 1725 & \begin{tabular}{|l|l|}
1725 \\
\end{tabular} & 1725 & 1725 & 1725 & \begin{tabular}{|l|l|}
1725 \\
\end{tabular} & 1725 & 1725 & 1725 & & & \\
\hline 25 & 1700 & 1700 & 1700 & 1700 & 1700 & 1700 & 1700 & 1700 & 1700 & 1700 & 1700 & 1700 & 1700 & 1700 & 1700 & 1700 & 1700 & 1700 & 1700 & 1700 & & \\
\hline 26 & 1650 & 1650 & 1650 & 1650 & 1650 & 1650 & 1650 & 1650 & 1650 & 1650 & 1650 & 1650 & 1650 & 1650 & 1650 & 1650 & 1650 & 1650 & 1650 & 1650 & 1650 & \\
\hline 27 & 1650 & 1650 & 1650 & 1650 & 1650 & 1650 & 1650 & 1650 & 1650 & 1650 & 1650 & 1650 & 1650 & 1650 & 1650 & 1650 & 1650 & 1650 & 1650 & 1650 & 1650 & 1637 \\
\hline
\end{tabular}

\section{Discussion}

The four most applicable methods that can be used to exit the conveyor from the pit include a dedicated ramp slot, highangle conveyor, tunnel, and existing truck ramps. Only the last method is considered in this paper. It is a well-known fact that when the existing haul roads are used to handle the materials, extra width would be needed to accommodate both truck and conveyor haulage routes. It is worthwhile to note that the truck fleet would be smaller after the primary crusher moves into the pit. In this situation, the transportation process will be easier to manage because of the lower traffic volume. To increase the final pit slope, in some cases, reducing road widths may be considered. On the other hand, incorrect haul road width at certain places causes bottlenecking and increased truck travelling times. A separate investigation of this aspect is needed. However, in this paper, it is assumed that the existing haul roads do not need to be widened in order to accommodate both conveyor and trucks on the same route.

As stated previously, the crusher must be in the centroid of the working faces. Relocation of the in-pit crushing station is required when the haulage distances become uneconomic for trucks. So, the other most important parameter affecting the problem is the relocation cost of the crusher, which involves the costs associated with disassembling the equipment, conveyor and crusher relocation costs, and the cost of purchasing additional equipment to increase the length of the conveyors. There must be a trade-off between these two costs (i.e. haulage operating cost and relocation cost). The crusher would not be relocated if the haulage operating costs can be reduced, since crusher relocation would not offset the relocation costs. More scenarios for relocation costs are considered to show other aspects of the proposed mathematical optimization model. The results are illustrated in Table VII. Changes in the value of this parameter in a range of \$1 million to \$5 million do not change the optimum locations significantly. However, increasing this parameter up to $\$ 30$ million reduces the number of relocations.

According to Table VI, depending on the year the mine installs the system, the exact timings of IPCC relocations are optimized. It is worth noting that, while there are some changes in the initial years, the optimum IPCC location in each year is somewhat independent of the IPCC's application time. The changes in the initial years are highlighted in Table VI.

The results in Tables VI and VII show that displacements occur most frequently in the final years. This means that the mine becomes deeper and operating costs are increased more rapidly than the earlier years.

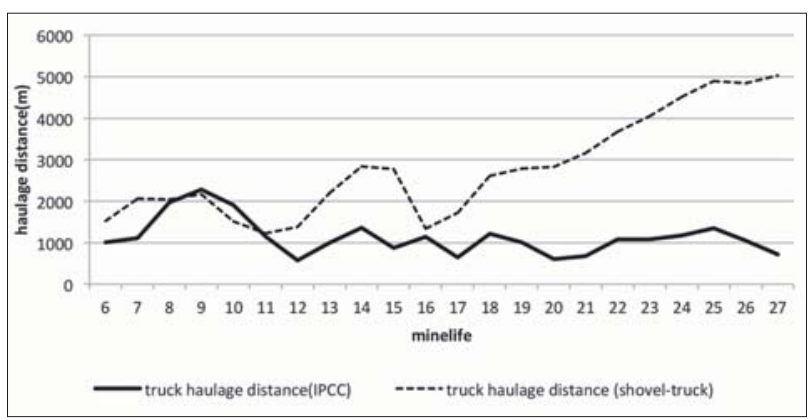

Figure 6-Comparison of truck haulage distances for both systems 


\section{In-pit crusher location as a dynamic location problem}

\begin{tabular}{|c|c|c|c|c|}
\hline Year & $\begin{array}{l}\text { Scenario } 1 \\
\text { (relocation cost } \$ 5 \text { million) }\end{array}$ & $\begin{array}{l}\text { Scenario } 2 \\
\text { (relocation cost } \$ 10 \text { million) }\end{array}$ & $\begin{array}{c}\text { Scenario } 3 \\
\text { (relocation cost } \$ 15 \text { million) }\end{array}$ & $\begin{array}{c}\text { Scenario } 3 \\
\text { (relocation cost } \$ 30 \text { million) }\end{array}$ \\
\hline 6 & 1912 & 1912 & 1962 & 1962 \\
\hline 7 & 1912 & 1912 & 1912 & 1962 \\
\hline 8 & 1912 & 1912 & 1912 & 1962 \\
\hline 9 & 1912 & 1912 & 1912 & 1962 \\
\hline 10 & 1975 & 1925 & 1912 & 1962 \\
\hline 11 & 1925 & 1925 & 1912 & 1962 \\
\hline 12 & 1925 & 1925 & 1912 & 1962 \\
\hline 13 & 1887 & 1887 & 1887 & 1887 \\
\hline 14 & 1825 & 1825 & 1825 & 1825 \\
\hline 15 & 1825 & 1825 & 1825 & 1825 \\
\hline 16 & 1912 & 1912 & 1912 & 1912 \\
\hline 17 & 1912 & 1912 & 1912 & 1912 \\
\hline 18 & 1862 & 1862 & 1862 & 1862 \\
\hline 19 & 1812 & 1812 & 1812 & 1812 \\
\hline 20 & 1812 & 1812 & 1812 & 1812 \\
\hline 21 & 1775 & 1775 & 1775 & 1775 \\
\hline 22 & 1775 & 1775 & 1775 & 1775 \\
\hline 23 & 1737 & 1737 & 1737 & 1737 \\
\hline 24 & 1725 & 1725 & 1725 & 1725 \\
\hline 25 & 1700 & 1700 & 1700 & 1700 \\
\hline 26 & 1650 & 1650 & 1650 & 1650 \\
\hline 27 & 1650 & 1650 & 1650 & 1650 \\
\hline $\begin{array}{l}\text { No. of } \\
\text { relocations }\end{array}$ & 12 & 11 & 11 & 10 \\
\hline
\end{tabular}

After determination of the best location and best time for relocation of the in-pit crusher, an accurate comparison of IPCC vs. pure truck systems will be possible. The comparison of the total haulage distance in the shovel/truck and IPCC systems is shown in Figure 6. In this figure, the IPCC is applied in the mine from the 6th year. In the case of the shovel/truck system, the total haulage distance will reach to more than $3000 \mathrm{~m}$ after year 20. However, in the case of the IPCC system, the total haulage distance by trucks inside the pit is always about $1000 \mathrm{~m}$. Thus, the IPCC system requires fewer trucks than the shovel/truck system. According to the results, this will save about $\$ 150$ million by the end of the mine life.

As the pit continues to deepen, additional movable conveyors will be installed at a lower elevation to dump on to the first conveyors. Therefore, the conveyor's periodical investment cost depends not only on the additional drive pulleys and motors needed, but also on the extra length of conveyor needed and the corresponding costs. These costs are a part of the relocation costs, which are considered here as an average of all probable scenarios for the extra conveyor required. This is calculated in the conveyor design process and preparing the input cost matrix (i.e. trucking, conveying, and relocation cost matrix) of the mathematical model. The capital costs of the IPCC system (purchasing the in-pit semimobile crusher and initial required conveyor length, engineering, commissioning, assembling, etc.) are not part of the crusher location and relocation problem. They are main factors affecting the time of application of IPCC.

Three main belt conveyor paths are required in the case study. The first one passes from the crusher to the ramping system, the second via the ramp system up to the pit rim, and the last across the rim (the existing ex-pit crusher) to the concentration plant. In this case, because of the special ramping system (switchback) additional transfer points may be required and extra costs may be incurred; however, this was not considered in this paper.

\section{Conclusion}

In-pit crushing-conveying (IPCC) has received renewed interest and is being reviewed by mining researchers worldwide. As pits become deeper and strip ratios increase, cost pressure on operations means that alternatives that incur lower operating costs become more attractive. Factors such as fuel prices, skilled labour shortages, truck costs, vehicle incidents, and greenhouse gas emissions force mining companies to change their transportation systems. Apart from choosing a suitable type of crushing and conveying system, the location of the system should also be optimized to reduce operating and capital costs. In addition, determination of the optimum time for relocating the system has not been considered to date. This time plays an important role in mine plan and cost reductions. In this study, determination of the optimum locations and optimum times for relocations of an in-pit crusher was studied as a dynamic location problem. The proposed method was implemented in a case study for Sungun copper mine.

According to Sungun's mining schedules and extraction sequences, haulage distances were calculated in each year. Two models were then developed to predict the haulage cost per ton per metre for both truck and conveyor systems. These models enable the mine planner to easily estimate the haulage costs with regard to increased haulage distance and times. 


\section{In-pit crusher location as a dynamic location problem}

Application of the IPCC system from year 6 will decrease the haulage costs by about $6 \%$ compared to the conventional shovel-truck system. This equates to about $\$ 150$ million through the mine life. In this case all the parameters were predicted using available data. In some cases, collecting the data is relatively hard, or even no data may be available, and the main parameters of the problem are likely to be uncertain during the planning horizon, and therefore models considering uncertainty would be of interest in such conditions. Future research should also be focused on dealing with the uncertainties.

\section{References}

Arabani, A.B. and Farahani, R.Z. 2012. Facility location dynamics: An overview of classifications and applications. Computers \& Industrial Engineering, vol. 62, no. 1. pp. 408-420. DOI: 10.1016/j.cie.2011.09.018

Benito, R. and Dessoreault, S. 2008. Estimation of incremental haulage cost by mining historical data and their influence in the final pit limit definition. Mining Engineering, vol. 60, no. 10. pp. 44-49.

Dos SANTos, J. 1987. In-pit crushing and high angle conveying in Yugoslavian copper mine. International Journal of Surface Mining, no. 1. pp. 97-104.

ERLENKOTTER, D. 1981. A comparative study of approaches to dynamic location problems. European Journal of Operational Research, vol. 6, no. 2. pp. 133-143.

Farahani, R. Z., Drezner, Z., and Asgari, N. 2009. Single facility location and relocation problem with time dependent weights and discrete planning horizon. Annals of Operations Research, vol. 167, no. 1. pp. 353-368.

Kavoshgaran Consulting Engineers. 2003. Sungun copper mine design report. Tehran. [In Persian].

KoenLer, F. 2003. In-pit crushing system the future mining option. Proceedings of Mine Planning and Equipment Selection (MPES) 2003, Kalgoorlie, Western Australia. Australasian Institute of Mining and Metallurgy, Melbourne. pp. 371-176.

KonaK, G., OnUR, A.H., and KaraKus, D. 2007. Selection of the optimum in-pit crusher location for an aggregate producer. Journal of the Southern African Institute of Mining and Metallurgy, vol. 107, no. 2. pp. 161-166.

LONERGAN, J.E. and BARUA, S.L. 1985. Computer-assisted layout of in-pit crushing/conveying systems. Proceedings of the SME-AIME Fall Meeting, Albuquerque, New Mexico, October.

MorRISS, P. 2008. Key production drivers in in-pit crushing and conveying (IPCC) studies. Proceedings of Surface Mining 2008, Southern African Institute of Mining and Metallurgy, Johannesburg. pp. 23-34.
Morrisson. D. and Lourel, I. 2009. In-pit crushing and conveying. Proceedings of the Iron Ore Conference, Perth, WA. Australasian Institute of Mining and Metallurgy, Melbourne. pp. 13-26.

Mular. A.L. 1992. Mining and Mineral Processing Equipment Costs and Preliminary Capital Cost Estimates. Canadian Institute of Mining, Metallurgy and Petroleum, Montreal

O'HARA, T.A. 1980. Ouick guides to evaluation of ore bodies. CIM Bulletin, vol. 73, no. 814. pp. 78-99

Osanloo, M. 2010. Surface Mining Methods. 3rd edn (revised version), vol. 2. Amirkabir University of Technology, Tehran.

Osanloo, M. 2012. Future challenges in mining division, are we ready for these challenges? Do we have solid educational program? Proceedings of the 23rd Annual General Meeting of the Society of Mining Professors, Poland. pp. 29-39.

Rahmanpour, M., Osanloo, M., Adibee, N., and AkbarpourShirazi, M. 2014. An approach to determine the location of an in-pit crusher in open pit mines. International Journal of Engineering (IJE) Transactions $C$, vol. 27, no. 9. pp. 14475-1484.p

RaYco, M.B., Francis, R.L., and TAmiR, A. 1999. A p-center grid-positioning aggregation procedure. Computers and Operations Research, vol. 26, no. 10. pp. $1113-1124$.

Roumpos, C., Partsinevelos, P., Agioutantis, Z., Makantasis, K., and Vlachou, A. 2014. The optimal location of the distribution point of the belt conveyor system in continuous surface mining operations. Simulation Modeling Practice and Theory, vol. 47. pp. 19-27

SCHRODER, D. 2003. The use of in-pit crushing and conveying methods to significantly reduce transportation costs by truck. Proceedings of CoalTrans Asia 2003, Bali International Conventional Center, 8-11 June. Indonesian Coal Mining Association.

Stughul, J. 1987. How to determine the optimum location of in-pit movable crushers. International Journal of Mining and Geological Engineering, vol. 5. pp. $143-148$

Turnbull, D. and COoper, A. 2009. In-pit crushing and conveying (IPCC) - a tried and tested alternative to trucks, Proceedings of the AusIMM New Leaders' Conference. Australasian Institute of Mining and Metallurgy, Melbourne. pp. 59-66.

Tutton, D. and Streck, W. 2009. The application of mobile in-pit crushing and conveying in large, hard rock open pit mines. Proceedings of the Mining Magazine Congress, Niagara on the Lake, White Oaks Centre, Toronto, Canada.

Zimmermann, E. 2006. Mobile crushing and conveying in quarries - a chance for better and cheaper production. Proceedings of the International Symposium on Continuous Surface Mining, Aachen. pp. 1-7.

\section{The SAIMM Journal all you need to know! \\ Less $15 \%$ discount to agents only \\ म PRE-PAYMENT is required \\ is The Journal is printed monthly \\ Surface mail postage included \\ ISSN 2225-6253}

\section{The SAIMM Journal gives you the edge!}

* with cutting-edge research

* new knowledge on old subjects

* in-depth analysis

\section{SUBSCRIBE TO 12 ISSUES January to December 2017 of the SAIMM Journal}
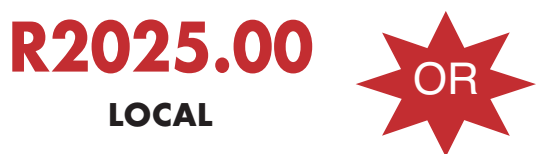

US\$520.00 OVERSEAS

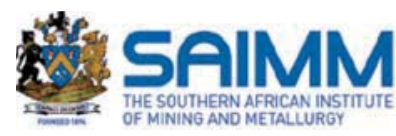

For more information please contact: Prudence Ntumeleng

The Journal Subscription Department

Tel: 27-11-834-1273/7 • e-mail: prudence@saimm.co.za or journal@saimm.co.za Website: http://www.saimm.co.za

\section{A serious, 'must read' that equips you for your industry-Subscribe today!}

